\title{
Regímenes políticos y sujetos: nuevos imaginarios en Viajes de D. F. Sarmiento
}

Palabras clave: Sarmiento, viajes, modelo social, EEUU, París,

\section{Introducción}

Sarmiento inicia su viaje rumbo a África, Europa y Estados Unidos en 1845 encargado por Manuel Montt, ministro chileno de instrucción pública, para estudiar en el extranjero el estado de la enseñanza primaria; sus publicaciones en prensa sobre educación le habían valido el reconocimiento del ministro, quien le dio la oportunidad de concretar el sueño de todo intelectual americano del siglo XIX: el viaje al viejo continente y, especialmente, a la ciudad de las luces, París.

Europa era en el imaginario americano un continente ambivalente: cuna de la civilización ilustrada, albergaba también sociedades retrógradas -como lo sería para Sarmiento, por ejemplo, España-; así lo expresa en su carta cuando desembarca en Ruan: «Eh! la Europa! triste mezcla de grandeza y de abyección, de saber y de embrutecimiento a la vez sublime y sucio receptáculo de todo lo que al hombre eleva o le tiene degradado, reyes y lacayos, monumentos y lazaretos, opulencia y vida salvaje!» (Sarmiento, 1949: 92). Sarmiento viaja con un imaginario bien definido por lecturas de diferente índole, las cuales diseñan una geografía política y social deseada y cuya máxima representante es, en principio, París.

Sin embargo, Sarmiento encontrará grandes contradicciones entre el país imaginado y el real, por lo que deberá reorganizar su búsqueda de un modelo. Es así que inicia un desplazamiento insperado, ya que el recorrido realizado en 1847 por Estados Unidos no era inicialmente un destino planeado dentro de 
su itinerario inicial: su viaje estaba casi finalizando (en especial, en el sentido económico) cuando descubre en Inglaterra el texto sobre sistemas educativos de Horace Manns, hallazgo que reorganiza su trayecto y le da una excusa para estudiar de cerca el sistema político estadounidense. ${ }^{1}$

Este punto es relevante ya que, si bien el objetivo declarado (y costeado) del viaje era analizar el desarrollo de la educación primaria en las capitales modernas, Sarmiento no pierde la oportunidad para juzgar y comparar los sistemas políticos de las sociedades que va atravesando, concibiendo de esta forma su propio proyecto político futuro: construir una nación a partir de su ingreso a la modernidad. Debido a este objetivo, su recorrido se constituye en lo que Julio Ramos (1989: 36) ha denominado viaje importador. ${ }^{2}$ Si para Sarmiento la Argentina era un territorio vacío sobre el que había que fundar una nueva nación, su experiencia y observación de las capitales de la modernidad le permitirían llenar ese vacío con modelos importados. ${ }^{3}$

Ambos aspectos de su viaje, el oficial - relacionado con la educación primaria- y el particular - vinculado con un país proyectado-, aunque con cauces evidentemente comunes, no podían ser expresados en el mismo texto ya que el tipo de desvíos que conllevaría el segundo podría importunar a los que financiaron el viaje. Por ese motivo, Sarmiento organiza el primero en un informe, texto autónomo que posteriormente se publicará como Educación Popular, y el segundo, es decir, sus reflexiones e impresiones más vívidas de los países recorridos, en sus cartas a sus amigos en Montevideo y Chile. ${ }^{4}$ Asimismo, el género

1 Para un análisis detallado de este hallazgo, véase Katra, William H. (1993): «Sarmiento en los Estados Unidos». En: Sarmiento D. F., Viajes por Europa, África y América (1845-1847). México: FCE. 853-911.

2 El primero en hablar de diferentes tipos de viajes (viaje colonial, viaje utilitario, viaje balzaciano, etc.) fue David Viñas, en su reconocido libro Literatura argentina y realidad política (1994). Sin embargo, creemos que la reformulación de esta categoría realizada por Julio Ramos en Desencuentros de la modernidad en América Latina (1989), se adecua mejor a la habitual inclasificación sarmientina.

3 El texto de Ramos afirma: «Ante la carencia de modelos el discurso se desliza, casi automáticamente, hacia su norte [...]. El intelectual en Sarmiento se legitima volviendo ,los ojos a todas partes buscando con qué llenar el vacío'». (Ramos, 1989: 36)

4 A ello se refiere David Viñas cuando afirma: «En Sarmiento el programa utilitario y las tentaciones estéticas coexisten pero con un componente inédito: el ímpetu del ritmo acelerador de su viaje europeo le permite controlar las dos vertientes organizándolas en obras separadas: «El fruto de mis investigaciones [sobre «el estado de la enseñanza primaria〉] verá bien pronto la luz» anuncia por un lado. Es Educación popular, que aparece en 1849 . „Pero dejaba esta tarea, árida por demás — prosigue-, vacíos en mi existencia ambulante“. Para llenarlos organiza sus Viajes y a partir de la estructura que les acuerda aparece la connotación que va definiendo su enfrentamiento con lo europeo». (Viñas, 1994: 36). 
epistolar le da la libertad de evitar la minuciosidad del informe (aunque intente ser exhaustivo) y de desplegar su escritura -de por sí grandilocuente y efusiva- manteniendo al lector contemporáneo en un continuo estado de asombro o deslumbramiento.

Ahora bien, Sarmiento no se limita a una importación servil: para realizar ese proyecto de país realiza un análisis, comparación y crítica -a veces, mordaz- sobre los modelos instituidos; observaremos cómo su viaje por algunas de las capitales europeas le deja un sabor agridulce: la utopía progresista de la Europa moderna no era más que eso, una utopía, y el escritor manifiesta esta desilusión en sus escritos. Este cambio de modelo es el que interesa al presente trabajo, en el cual se intentará analizar cómo se produce este giro a partir de la lectura de París, carta del 4 de septiembre de 1846, y EEUU, carta del 12 de noviembre de 1847 , final de los viajes. Proponemos, además, que ésta última constituye un esfuerzo retórico por parte de Sarmiento que organiza su descripción y narración en función de su objetivo de proponer un nuevo modelo y de captar al receptor al convencerlo de que esa perspectiva es incuestionable.

\section{Ciudad imaginada / ciudad real}

La ciudad de las luces deja una impresión contradictoria en Sarmiento; su recorrido por París es un viaje simultáneo hacia diferentes destinos con resultados diversos: el primero es la ciudad cosmopolita y moderna, aquella que deslumbra al viajero americano; el segundo, la ciudad política, cuyo sistema parlamentario graba una impresión negativa en el ideólogo y publicista; y el tercero, la ciudad de los escritores, donde el autor intentará insertarse. ${ }^{5}$

París es el centro cultural de esa «Francia de nuestros sueños» (Sarmiento, 1949: 89), por lo tanto, lo primero que tendrá que emparejar Sarmiento será su imaginario sobre ella y la realidad de la ciudad; los discursos que lo habitan son variados, pero un caudal importante proviene de la literatura, la cual ha construido un imaginario que la mitifica. Sin embargo, debe desestimarla rápidamente:

Desde luego, si ve Ud. a mis amigas en Santiago, dígales de mi parte que no está aquí en este momento Eugenio Sue; pero que me han mostrado al rengo Tortillard [...]. Brazorrojo se

5 Por razones de extensión y para concentrar el análisis sobre la alteración del modelo, no se abordará en el presente artículo al Sarmiento escritor; se espera abordar este punto en trabajos posteriores. 
ha hecho honrado con su contacto con la policía, y la Rigolette goza de una grande reputación en el baile Mabille. ¡Otras pérdidas mayores aun tenemos que deplorar! No hay ya ni aquellas pocilgas y vericuetos donde los Misterios comienzan. (Sarmiento, 1949: 102)

El viajero no encontrará a esa París descrita sólo algunos años antes por Eugène Sue en Los misterios de París; la ciudad se ha renovado y modernizado, se ha llenado de luces a gas y tiendas «coquetas como novias». En este sentido, Sarmiento se asume como el extranjero aturdido por «el espíritu parisino», fascinado por sus flâneur y su arte de mirar, por su sociabilidad y cordialidad, y por su arte y conocimiento: «Je flâne, yo ando como un espíritu, como un elemento, como un cuerpo sin alma en esta soledad de París.» (Sarmiento, 1949: 109)

Encuentra a tal punto sorprendente la indulgencia pública hacia el extranjero que duda de que se trate del mismo pueblo que hizo la revolución; es así, que inicia una búsqueda de los signos del pueblo de las grandes ideas. Se convierte en un coleccionista de signos y posteriormente en un criptólogo que descifra esos signos para los receptores de su carta. El primero será el flâneur; el segundo, la cordialidad; dirá, por ejemplo, respecto de la educación de los ciudadanos: «En otro signo he reconocido el pueblo de las grandes cosas, el brazo de hierro de las ideas. Aquel francés [...] es el hombre más blando, más atento, más cometido» (Sarmiento, 1949: 109). Esta «benevolencia pública» es uno de los signos de la sociedad civilizada más acentuado par el viajero: «He aquí la piedra de toque de la cultura intelectual de una nación, aunque no sea la instrucción del individuo» (Sarmiento, 1949: 111). Estos juicios permiten identificar además cómo la perspectiva ha comenzado a girar: ya no es el simple viajero el que juzga, sino el político e ideólogo que busca las claves para la fundación de una nación civilizada. En este sentido, la introducción de la carta y su respuesta a los reproches que el Dr. Aberastain le había realizado sobre sus impresiones anteriores -quien lo acusa de escribir sobre cosas poco prácticas para América-, le sirve como excusa para definir su rol de autoridad fundada en sus antecedentes, desde el cual se constituirá como voz autorizada y experimentada:

¡Cómo! ¿A mí se dirigen estos consejos? ¿Era Ud., por ventura, quien en San Juan, construía máscaras en carnaval, fundaba en mala hora colegios, y creaba el Zonda, aquel diario indigno que los patriotas por las injurias que hacía al decoro, al honor y a la fama de la provincia en el Universo y en otros lugares? 
¿Era Ud., doctor, el que iba a la cárcel antes de pagar los doce pesos que el Podestá nos cobraba inconstitucionalmente [...]? (Sarmiento, 1949: 107)

Es así que Sarmiento establece su autoridad como político, educador, publicista y defensor de la ley, es decir, no sólo como hombre teórico, como ideólogo, sino también como hombre práctico y con experiencia sobre los problemas de gobierno en los nuevos países americanos.

Esto lo capacita para emitir los severos juicios que pronunciará sobre la ciudad política y su sistema de gobierno; pronto descubre los primeros signos de decadencia del modelo francés: «Diría Ud. que el mundo político está para acabarse; todos los signos son de un cataclismo universal» (Sarmiento, 1949: 112). ¿Dónde quedó el Sarmiento qué exclamaba en cartas anteriores que Francia era «el modelo de todos los bastardos edificios que se están levantando en América» (1949: 113)? Ya ha descubierto las primeras grietas, pero la ruptura sólo vendrá luego de las decepcionantes entrevistas con Dessage, Guizot y el barón Mackau, y la pantomima política observada en la Cámara de Diputados.

Las entrevistas referidas tienen una importancia capital para que Sarmiento cobre total conciencia de cómo se manejaban y evaluaban los asuntos rioplatenses en Francia: no sólo reina el desinterés general, sino, y aún peor, la desinformación y tergiversación de las noticias relevantes. La parcialidad hacia el rosismo que manifiestan los ministros a pesar de los intentos de Sarmiento de alterar esa percepción lo dejan desolado: «Aquí tiene Ud. pues, íntegro el pensamiento oficial sobre la cuestión del Río de la Plata, en el gabinete de la Tullerías, jarrón dorado que contiene agua sucia. Dessage, Alley, tales como Ud. los ve, son los árbitros de nuestra suerte» (1949: 118).

Si bien la entrevista que mantiene con Adolphe Thiers logra animarlo, la invitación a escuchar su discurso en la Cámara termina por determinar el juicio negativo que emitirá sobre el debilitado sistema de gobierno francés. Allí Sarmiento se concentrará en su rol de descifrador: no importan tanto los discursos emitidos por los oradores, como los efectos que producen; así, los representantes son animalizados por esa mirada que sólo registra lo gestual: si Mackau era «un animal en dos pies», la Cámara no será más que un «reñidero de gallos de dimensiones colosales» (1949: 121).

La descripción del funcionamiento habitual de este órgano de gobierno no hace más que poner en evidencia que se ha falseado en una pantomima de lo que se suponía que era: 
Léese la orden del día, sube un orador a la tribuna, y el chas, chas de los papeles agitados intencionalmente comienza; nuevos oradores y más o menos bulla según el color a que pertenecen; un diputado joven decía: ipero, por Dios señores, permítanme decir una sola palabra! ¡Hum! ¡qué ruido, qué risa! Al fin el orador desciende riéndose también. (Sarmiento, 1949: 122)

Las instituciones se han convertido en una representación desviada de sus funciones. Sarmiento identifica el síntoma de una enfermedad mayor y aún contagiosa: la corrupción. Thiers la denuncia en su discurso, pero pocos se sienten a salvo del ataque, pues es la práctica corriente instaurada por el ministro François Guizot:

He aquí el secreto del gobierno de M. Guizot, porque se observa que todas las listas principian en 1840 [...]. Los electores eran 490, y los dones repartidos son 304, éstos van a los hijos, a los hermanos, a los allegados de los electores de campaña, aquellos buenos paisanos, la petite propriété de M. Dessage, aquellos sostenedores del orden, puesto que siembran patatas. La Francia ha caído en este horrible lazo, y en vano se agita, lucha, protesta; ella no es el país legal, ni el país electoral. [...] Cuando se denuncia en el tribuna un delito evidente como la luz, una dilapidación escandalosa, probada, M. Guizot pide que la cámara decida si está o no satisfecha, y un movimiento en masa de la turba de cómplices, absuelve de toda culpabilidad al rey y al ministro. ¡He aquí el país legal, he ahí los grandes hombres de la tierra! (Sarmiento, 1949: 127)

Diagnostica así el fracaso de la revolución, ya que una monarquía constituyente ha desfondado todos sus principios: los hombres no son iguales ante la ley, el poder no es dado por la soberanía popular, la fraternidad sólo existe con dones o favores de por medio. El golpe es duro, pero Sarmiento hace una evaluación devastadora sobre lo que ha observado: la fuente del mal que aqueja a Francia es su ley electoral: el sistema de representantes falla porque los individuos son elegidos «según lo que poseen y no según lo que saben». Por último, la monarquía sólo ha perdido poder en los papeles; los hechos demuestran un rey que tiene mayoría en la cámara y un defensor acérrimo por ministro.

Este panorama decepcionante no logra opacar del todo la ilusión francesa: la sociabilidad de sus ciudadanos viene al rescate de un imaginario resquebrajado, 
aunque no liquidado completamente; es así que los bailes públicos serán uno de los últimos signos de que el país de las grandes ideas aún vive:

[...] pero hay aun otro costado de París que me ha llamado profundamente la atención, y son los placeres públicos, y la influencia que ejercen sobre las costumbres de la nación. Aquí donde la inteligencia humana ha llegado a sus últimos desenvolvimientos, donde todas las opiniones, todos los sistemas, las ciencias como las creencias, las artes como la imaginación marchan en líneas paralelas...(Sarmiento, 1949: 134)

Los bailes públicos son los que incitan estas reflexiones ya que para Sarmiento constituyen una manifestación del espíritu igualitario: todos los ciudadanos son aceptados allí como iguales y las clases desaparecen momentáneamente, los locales están decorados lujosamente e iluminados por lámparas a gas y la música de los maestros está disponible para todos. Esta es una de las tantas iniciaciones en la civilización a la que están expuestos los franceses y que desarrollan su espíritu. La mirada del ideólogo no puede más que recocer este signo como un instrumento: « $i$ Qué poderoso instrumento puesto en manos hábiles!» (Sarmiento, 1949: 137)

La búsqueda del modelo en el sistema político francés recibe un fuerte revés que debilita considerablemente su elección; sin embargo, sólo la observación directa de Sarmiento sobre Estados Unidos hará que ese modelo sea definitivamente reemplazado. Aún la sociabilidad y la cultura francesa seducen al ideólogo; faltará la experiencia norteamericana para cancelarlo definitivamente.

\section{La mirada selectiva ${ }^{6}$}

Hemos mencionado ya que el viaje a EEUU fue más una necesidad que un proyecto largamente meditado: la experiencia europea sólo logró que Sarmiento expandiese su búsqueda hacia nuevos puertos. El descubrimiento de un naciente modelo para los países sudamericanos conllevó abandonar un paradigma instituido en el imaginario rioplatense, por lo que el autor no podía más que prever el rechazo que su nueva propuesta recibiría. La carta que envía a Alsina, por lo tanto, es una elaborada argumentación a favor de este nuevo modelo, no universalizado aún, de sociedad moderna que intenta promover.

6 Una versión preliminar de este apartado se encuentra publicada: «La mirada selectiva: Estados Unidos de D. F. Sarmiento». En: María Coira, Rosalía Baltar y Carola Hermida (Eds.) (2012): Escenas interrumpidas de la literatura argentina II. Imágenes del fracaso, utopias y mitos de origen en la literatura nacional. Buenos Aires: Katatay Editores, 129-140. 
Por eso, si bien la carta que narra el viaje por la joven nación americana tiene un destinatario definido, está construida con la previsión de que será publicada para un público masivo (dentro de los límites de la masividad periodística de siglo XIX), por lo cual Sarmiento aprovecha las posibilidades del género para presentar las ideas bases de lo que será su proyecto futuro.

La descripción de Estados Unidos se encuadra, por lo tanto, dentro de esta argumentación cuidada que va recorriendo diferentes puntos: la riqueza de la naturaleza y los beneficios productivos - desde la abundancia de productos hasta las ventajas de un sistema de comunicación fluvial altamente explotado-; el desarrollo científico y la innovación en su progreso -productos e inventos que son exportados hacia todas la naciones modernas europeas-; y el carácter de sus ciudadanos y su afán de desarrollo y progreso, fundamentado a partir de la defensa de la educación y la participación como medios de desarrollo.

La estrategia retórica de Sarmiento para abordar estos ejes se funda en una premisa básica que sostendrá a todas las demás, EEUU es una realidad nueva:

Los Estados Unidos son una cosa sin modelo anterior, una especie de disparate que choca a primera vista, y frustra la expectación pugnando contra las ideas recibidas, y no obstante, este disparate inconcebible es grande y noble, sublime a veces, regular siempre [...]. No es aquel cuerpo social un ser deforme, monstruo de las especies conocidas, sino como un animal nuevo producido por la creación política, extraño como aquellos megaterios cuyos huesos se presentan aún sobre la superficie de la tierra. (Sarmiento, 1949: 333)

El énfasis en la novedad del objeto que presenta lo autoriza a trabajar con él sin restricciones ya que no existen muchos discursos que sirvan como antecedente al lector; esto le permite modelarlo a su conveniencia y recortar los aspectos más asombrosos para un lector contemporáneo. De esta forma, apunta a un doble efecto: por un lado, anticipar las objeciones de posibles receptores sobre lo que va a describir, admitiendo su propia turbación y, de esta forma, establecer una suerte de reacción en común que acompañe la posterior muda de modelo; por el otro, manejar el objeto Estados Unidos en el campo de lo sorprendente, deslumbrando a partir de la acumulación de señales de riqueza y progreso.

La novedad trae como corolario las dificultades para interpretar esa nueva creación política: 
De manera que para aprender a contemplarlo, es preciso antes educar el juicio propio, disimulando sus aparentes faltas orgánicas, a fin de apreciarlo en su propia índole, no sin riesgo de, vencida la primera extrañeza, apasionarse por él, hallarlo bello, y proclamar un nuevo criterio de las cosas humanas. (Sarmiento, 1949: 333$)^{7}$

Dentro de este paradigma de educar el juicio no puede faltar la figura del educador y quién mejor que él para definir esos sentidos ambiguos, constituyéndose como un guía/narrador fuertemente dominante. Gracias a este manejo, Sarmiento se construye nuevamente - tal como hizo en París- como la voz autorizada para definir lo que es relevante y disimular lo que no lo es, y de esta forma, posicionarse respecto de sus propias aspiraciones para sí. De esta forma, se constituye como demiurgo de una nación: a diferencia del caso francés, donde su imaginario estaba sobrepoblado de lecturas e interpretaciones, describir esta realidad nueva es crearla con palabras para sus lectores, e incluso su discurso adquiere tono superlativo cuando hipotetiza sobre su propio lugar en un posible proyecto de país: «Si dios me encargara de formar una gran república...». (Sarmiento, 1949: 335) Efectivamente, Sarmiento proyecta que su función a futuro será formar una gran república, y con estas miras construye retóricamente su carta para asegurar la adhesión no sólo al modelo, sino también al ideólogo que lo propone.

La construcción que exalta los atributos de ese objeto se realiza a partir de la selección de lo que podríamos denominar objetos-símbolos, es decir, de objetos en apariencia triviales, pero que importan por lo que connotan para un lector que no conoce directamente esos fenómenos observados. Por ejemplo, la profusión de caminos y medios de transporte importan como indicio del deseo de progreso económico y del desarrollo de la infraestructura; la vivienda fabricada con ladrillos, incluso en las aldeas más alejadas, es señal de la distribución equitativa de la riqueza; la construcción de los trenes con comodidades uniformes para todos los vagones es marca de la igualdad que gozan todos los ciudadanos; la producción masiva y artística de carteles señalizadores, indica la distribución equitativa del conocimiento y la educación. De esta forma, Sarmiento no se contenta con enumerar esos fenómenos para asombrar al lector, sino que su voz establece los significados que deben asociarse a estos

7 El mismo argumento había utilizado ya en su Prólogo a los viajes para referirse a los pueblos civilizados europeos: «Nuestra percepción está aún embotada, mal despejado el juicio, rudo el sentimiento de lo bello, e incompletas nuestras nociones sobre la historia, la política, la filosofía y las bellas letras de aquellos pueblos...» (Sarmiento, 1949: 9). 
objetos seleccionados, determinando a su vez su interpretación positiva en pos de una consideración favorable del modelo norteamericano:

Los anuncios en los Estados Unidos son por toda la Unión una obra de arte y la muestra más inequívoca del adelanto del país. Me he divertido en España y en toda América del Sud, examinando aquellos letreros donde hay, hechos con caracteres raquíticos y jorobados y ostentando en errores de ortografía la ignorancia supina del artesano o aficionado que las formó. (Sarmiento, 1949: 344)

Obsérvese que Sarmiento toma un dato aleatorio, como en este caso las letras de los carteles, y lo convierte en indicio de aspectos sociales y culturales, como dato en un estudio antropológico de la sociedad norteamericana. Similar propuesta había realizado en Facundo, enunciando los símbolos de la barbarie y los de la civilización; también en este texto, entonces, la interpretación sarmientina selecciona símbolos de modernidad y progreso. ${ }^{8}$ La diferencia fundamental con Facundo es que, mientras en el primero regía una interpretación dicotómica de la realidad nacional, civilización-barbarie, y proponía los símbolos que la hacían presente, algunos años después, su experiencia de viaje produce un giro en su pensamiento, advirtiendo así las complejidades profundas que encierra la cuestión social: la civilización (Francia) puede correr el riesgo de fracasar, y la barbarie no necesariamente debe/puede modificarse en el tiempo (el caso Argelia, por ejemplo). La ciudad norteamericana, por lo tanto, se constituye para este escritor en el símbolo de modernidad, en único ejemplo de sociedad que ha podido llevar a cabo exitosamente la experiencia de la República. Asimismo, esos objetos, los carteles señalizadores, le permiten comparar la situación en Norteamérica y España y así utilizar para desprestigiar al segundo en algo que podría llegar a percibir cualquier viajero, pero que está elevado al nivel de observación seudocientífica al ponerlo como señal de algo más.

Esta estrategia es utilizada para persuadir al lector del fundamento racional de su proyecto, y establece para ello un sistema de comparaciones entre esos objetos-símbolos seleccionados y los prototipos conocidos: por un lado, lo que

8 Respecto de la interpretación simbólica que realiza Sarmiento en Facundo, Arturo Roig afirma: «La realidad social, como hecho conflictivo, se pone de manifiesto en un complejo mundo de contrarios. $\mathrm{Y}$ a su vez estos contrarios se expresan a través de sus símbolos o son directamente símbolos. ¿Cómo se entiende lo simbólico en Sarmiento? El símbolo es un significado segundo, una direccionalidad semántica particular dada a cualquier signo. También las palabras son utilizadas como símbolos. La estructura nos muestra una organización de sistemas antagónicos de símbolos.» (Roig, 1986: 168) 
se propone como el modelo a imitar, Estados Unidos; por otro, lo que se quiere dejar atrás, es decir, Europa (entendida como Francia e Inglaterra principalmente) y las nuevas naciones americanas. Por ejemplo, Sarmiento explica:

Hago estas comparaciones para mostrar la diversa atmósfera en que se educa el pueblo y la energía moral y física que desenvuelve. En Francia hay tres categorías de vagones, en Inglaterra cuatro, [...] En los Estado Unidos el vagón es [uno]: las comodidades y los cojines son excelentes e iguales, y por lo tanto el precio del pasaje es el mismo para todos. [...] Así se educa el sentimiento de igualdad, por el respeto al hombre. (Sarmiento, 1949: 368)

Lo relevante de este esquema es que, de una configuración bipartita de las posibilidades de sociedad presentadas en el Facundo (Francia/ Argentina) -con sus correspondencias dentro de su propuesta de civilización y barbarie-, en este texto se pasa a una propuesta tripartita de comparación: Estados Unidos, Europa, Argentina. Esta es una estrategia que sirve para acentuar lo favorable de su propuesta por ser superadora del modelo reconocido; así, realiza cotejos sobre diversos puntos: tutela del Estado en Europa versus libertad política y económica del individuo en Norteamérica; masas analfabetas y pobres versus distribución equitativa de la riqueza y la educación; división y degradación en clases sociales versus confort generalizado y trato igualitario, etc. La comparación le sirve para socavar el modelo institucionalizado, y exaltar aquellos aspectos que serían deseables para un proyecto de país.

Esta exaltación de su modelo tiene como corolario una presentación idealizada de Norteamérica: carece de defectos relevantes - los pocos que menciona sólo los refiere para refutarlos-, no posee conflictos graves -todo se resuelve democráticamente ya que sus ciudadanos tienen el modelo político interiorizado como propio- ni carencias importantes - cualquier pequeña aldea es en comparación más rica que una ciudad americana-.

De esta forma, diseña e identifica el modelo del ciudadano yanqui: educado, con libertad para expresar sus ideas, propietario e involucrado en las decisiones políticas. Los norteamericanos no arrastran la pesada tradición del antiguo régimen, como sí lo hacen los países sudamericanos; no tuvieron una monarquía retrógrada dominando las colonias que fueron su base. Sarmiento realiza ahora un nuevo dictamen, tal como lo hizo con el modelo francés: este es el corazón del éxito de Estados Unidos, el carácter de sus ciudadanos: 
La estadística de los Estados Unidos muestra el número de hombres adultos que corresponden a veinte millones de habitantes, todos educados, leyendo, escribiendo, y gozando de derechos políticos [...], el hombre con sentimientos y necesidades políticas; el hombre en fin dueño de sí mismo, y elevado su espíritu por la educación y el sentimiento de dignidad. (Sarmiento, 1949: 363)

Así, la idealización del modelo se acompaña también con la construcción hiperbólica de todos sus aspectos, desde la riqueza natural hasta la conciencia política de sus habitantes. Sarmiento presenta a Norteamérica como el país soñado convertido en realidad, el ideal de sujeto moderno encarnado en ciudadanos concretos, y la riqueza natural explotada en producción útil.

Por otra parte, respecto a la ya mencionada omisión de aspectos negativos, hay que recordar que Norteamérica era un país en expansión territorial. Cuando Sarmiento narra la conquista del territorio (que adelanta las que se darán en la Argentina) no hace mención a los despojos y opresión, a la corrupción en los pueblos de frontera ni a las condiciones de violencia habitual; tampoco examina las condiciones de vida de los obreros de las fábricas, ni las diferencias sociales entre los que tienen las grandes plantaciones y los esclavos (aunque menciona someramente el asunto). Así, si bien puede adjudicarse a la brevedad de su estadía en el país, podría afirmase que se omiten -consciente o inconscientemente- en función de la imagen sublimada que promociona: un ideal país moderno, donde sus conquistas son valientes aventuras en pos del progreso y ejemplo de gobierno. Así, por ejemplo, los que viajan al Far West son colonos rectos que fundan naturalmente municipios con un sistema democrático y resuelven sus conflictos racionalmente:

Este pueblo lleva, como Ud. ve, en su cerebro, orgánicamente, cual si fueran una conciencia política, ciertos principios constitutivos de la asociación: la ciencia política pasada a sentimiento moral complementario del hombre, del pueblo, de la chusma; la municipalidad convertida en regla de asociación espontánea; la libertad de conciencia y de pensamiento; el juicio por jurados. (Sarmiento, 1949: 382)

Otro aspecto a señalar respecto de esta carta es que, junto al desborde que por momentos toma su escritura por sus manifestaciones admirativas -se 
multiplican las exclamaciones, las interrogaciones retóricas y las apelaciones al receptor-, y sus opiniones y críticas -especialmente las que apuntan a la construcción antinómica en función de marcar las deficiencias del modelo europeo-, otra vertiente encauza el discurso a partir de la incorporación de datos, cifras y estadísticas que son presentadas como pruebas de su planteo:

Gracias a sus desvelos, el Estado de Massachusetts, de que es Boston la capital, contenía en 1846 , en las trescientas nueve ciudades y villas que lo forman, 3.475 escuelas públicas, con 2.589 maestros hombres y 5.000 maestras, asistidas por 174.084 niños. Observe Ud. que el número de maestros de escuela es mayor en este Estado que el monto total del ejército permanente de Chile, y el tercio del de todos los Estados Unidos. (Sarmiento, 1949: 451)

Este tipo de datos juegan un papel fundamental cuando se enfrenta a ciertos paisajes naturales que logran conmoverlo, como ocurre con las cataratas del Niágara, y su aspiración romántica asoma indefectiblemente en su discurso. En esos casos, Sarmiento recurre a los datos numéricos para computar esa realidad y controlarla, logrando utilizarla para su argumentación. Al respecto, David Viñas (1998: 15) opina que «Si la naturaleza loca es la barbarie, el exorcismo estadístico se convierte en ciencia».

Podemos afirmar, finalizando, que la carta a Alsina ha sido compuesta por Sarmiento como una elaborada argumentación que utiliza una variedad de recursos -selección de objetos-símbolos y determinación de sus significados, fabricación de un sistema de comparaciones, construcción idealizada e hiperbólica de lo observado, uso de la estadística y las cifras- para, no sólo proponer un nuevo modelo de sociedad moderna a imitar y/o trasplantar al contexto nacional, liquidando los modelos que sirvieron de inspiración para los ideólogos revolucionarios, sino también para legitimar su propio lugar respecto de ese proyecto de nación.

\section{Claves para el enigma rioplatense: el nuevo sujeto político}

Las cartas seleccionadas de los Viajes de Sarmiento evidencian una preocupación en común e intentan dar respuesta a uno de los enigmas que atravesaron el siglo XIX: cómo construir un régimen político fundado en la soberanía popular. El problema de la representación y de la legitimidad del poder es 
expuesto en ambas al analizar dos formas de gobierno: la monarquía constitucional francesa y la democracia norteamericana. Como hemos señalado, Sarmiento queda profundamente decepcionado por lo atestiguado en París, pero sólo abandona a Francia como modelo luego de vivir la experiencia de Estados Unidos.

Estos textos se encuentran en los extremos de su viaje; mucho ha experimentado, analizado y reflexionado ya sobre los países que visitó. Sin embargo, podemos mencionar que la falla que identifica en Francia representa de alguna forma las del modelo europeo en su conjunto: falta de representatividad de su gobierno, corrupción, distribución inequitativa de los bienes económicos y culturales, intentos de censura en la prensa, etc. Debemos recordar que en 1846, cuando Sarmiento visita París, ya se estaba viviendo el malestar político por la falta de legitimidad en la representación que derivaría en la revolución de 1848 .

Este diagnóstico demoledor de Francia es el que promueve con mayor éxito el modelo norteamericano, el cual aparentemente ha logrado las condiciones deseables para una sociedad moderna: un sujeto político autónomo, sin tutores ni restricciones en su práctica política, religiosa, económica ni social. Sarmiento identifica aquello que ha permitido este nacimiento original: una tradición monárquica extremadamente diferente a la española y a su religión represiva, y la instauración de hábitos modernos, como la libre circulación de información por medio de la prensa diaria - la cual ayuda al desarrollo de la opinión pública y regula el poder-, la igualdad en distribución de la riqueza y las oportunidades de negocios, la alfabetización de sus ciudadanos, y el estímulo de la participación política.

El modelo que descubre en Estados Unidos es el que propone finalmente para Argentina; sin embargo, las diferencias en las tradiciones y en la fisonomía de los habitantes eran demasiado claras como para que se efectúe un traslado directo. Era evidente que una propuesta como esa sólo podría llevar al fracaso y al retraso del desarrollo de la sociedad; es por ello que Sarmiento promueve $\mathrm{y}$, luego, cuando ya se encuentra de regreso en el país cumpliendo funciones políticas, pone en práctica una transformación de los individuos a partir de la educación; la apuesta sarmientina será, entonces, la transformación de lo social. La utopía pedagógica encuentra así la prueba de su efectividad en el modelo norteamericano y se asume como la estrategia privilegiada para introducir a los países sudamericanos en la modernidad. 


\section{Bibliografía}

Baczco, B. (1991) [1984]: Los imaginarios sociales. Memorias y esperanzas colectivas. Buenos Aires: Nueva Visión.

Katra, W. H. (1993): «Sarmiento en los Estados Unidos». En: D. F. Sarmiento, Viajes por Europa, África y América (1845-1847). México: Fondo de Cultura Económica, 853-911.

Ramos, J. (1989): Desencuentros de la modernidad en América latina. Buenos Aires: Fondo de Cultura Económico.

Roig, A. A. (1986): «El Facundo como anticipo de una teoría del discurso». En: El pensamiento latinoamericano en el siglo XIX. México: IPGH.

Roldán, D. (2006): «Sarmiento y el viaje a Argelia. Entre el inmovilismo y la utopía social». En: Batticuore, G., Gallo K. y Myres J. (comps.), Resonancias románticas. Ensayos sobre bistoria de la cultura argentina (1820-1890). Buenos Aires: Eudeba, 199-210.

Sarmiento, D. F. (1949): Viajes por Europa, América y África en Obras completas (tomo V). Buenos Aires: Luz del Día.

Sarmiento, D. F. (2005) [1845]: Facundo. Civilización y Barbarie. Buenos Aires: Bureau Editor.

Silvestri, G. y Aliata F. (2001): «Introducción». En: El paisaje como cifra de armonía, Buenos Aires: Nueva Visión.

Viñas, D. (1977): De Sarmiento a Cortázar. Buenos Aires: Siglo Veinte.

Viñas, D. (1994): Literatura argentina y realidad política, Tomo I. Buenos Aires: CEAL.

Viñas, D. (1998): De Sarmiento a Dios. Viajeros argentinos a USA. Buenos Aires: Editorial Sudamericana. 


\section{Political regimes and subjects: new imaginaries in Viajes of D. F. Sarmiento}

Keywords: Sarmiento, travel, society model, United States, Paris.

The accounts of D. F. Sarmiento's journey to Europe and USA have attracted the attention of literary critics since their publication because of the political project that they proposed and their exceptional rhetorical construction. His project responded to a major concern of the Río de la Plata intellectuals: the creation of a new country and the inauguration of a new political phase of order and progress which would put an end to Argentinian political instability. The answer to this question lays for Sarmiento in the study and importation of European society models. However, while he was travelling through Europe, he experienced a change in his perspective and he started to look to North American society. This change is the main point of interest of this paper in which the author proposes a discursive analyses of how that change is expressed in two letters: "Paris", sent on September $4^{\text {th }}$ of 1846 -at the beginning of his travel- and "USA", sent on November $12^{\text {th }}$ of 1847 -his last stop. In the last letter Sarmiento also proposes a new society model, the North American one, and tries to persuade the reader, with rhetorical and argumentative means of the adequacy of this model. 
Virginia P. Forace

Universidad Nacional de Mar del Plata - CONICET

\section{Politični režimi in subjekti: novi imaginariji v Viajes D. F. Sarmienta}

Ključne besede: Sarmiento, potovanje, družbeni model, Združene države Amerike, Pariz

Potopisi D. F. Sarmienta so med kritiki zbudili pozornost takoj, ko so bili objavljeni, ker je v njih zagovarjal določen politični projekt ter zaradi retorične in diskurzivne spretnosti. Večina intelektualcev Ría de la Plata si je močno želela ustanoviti državo ter začeti obdobje reda in napredka, ki bi ukinilo argentinsko politično nestabilnost. Pri Sarmientu je bilo iskanje odgovorov usmerjeno $v$ študij in pomen evropskih modelov. Vendar pa se je med potovanjem preusmeril na nov, severnoameriški družbeni model, ki ga je navdihoval. Ta sprememba je središče zanimanja pričujočega prispevka, v katerem skuša avtorica na ravni diskurza analizirati, kako pride do tega obrata, in sicer na osnovi branja dveh besedil, ki sta značilni za dva nasprotna si pola njegovega potovanja: »Pariz«, pismo z dne 4. septembra 1846, ki pomeni prvotno približevanje Evropi, in $\gg \mathrm{ZDA} \ll$, pismo z dne 12. novembra 1847, ki pomeni konec potovanj. V zadnjem pismu Sarmiento predlaga nov družbeni model, in sicer severnoameriškega, ter z retoričnimi in literarnimi sredstvi skuša prepričati bralca o primernosti tega modela. 